\title{
PRODUÇÃO DE GOMA XANTANA A PARTIR DE SORO DE LEITE
}

\author{
M. R. M. F. da $\operatorname{COSTA}^{1}$, E. R. NUCCI ${ }^{1}$ e E. N. OLIVEIRA Jr ${ }^{1}$ \\ ${ }^{1}$ Universidade Federal de São João Del Rei, Departamento de Química, Biotecnologia em \\ Engenharia de Bioprocessos. \\ E-mail para contato: eniobio@ufsj.edu.br, mariaritameyer@yahoo.com.br
}

\begin{abstract}
RESUMO - A goma xantana é um polissacarídeo produzido por bactérias gramnegativas do gênero Xanthomonas. Essa goma tem grande importância comercial e pode ser utilizada como estabilizante, emulsificante e espessante em alimentos. É amplamente utilizada devido às suas características reológicas, como capacidade de alterar as propriedades básicas da água, além de possuir alta viscosidade em baixas concentrações, estabilidade em uma ampla faixa de temperatura, $\mathrm{pH}$ e concentração de sais. O objetivo do trabalho foi avaliar o rendimento da produção de goma xantana pela bactéria Xanthomonas campestris utilizando como substrato alternativo o soro de leite sob diferentes condições de volume de soro e volume de inóculo. Os resultados foram comparados com a goma produzida a partir de meio padrão de sacarose. A média encontrada pelo experimento com a sacarose foi de $1,33 \mathrm{~g} . \mathrm{L}^{-1}$ e de soro de leite foi de $2,97 \mathrm{~g} . \mathrm{L}^{-1}$. Esse resultado indica que é possível produzir goma xantana a partir do meio alternativo analisado utilizando um subproduto da indústria de laticínios.
\end{abstract}

\section{INTRODUÇÃO}

As gomas são substâncias poliméricas capazes de formar dispersões, soluções altamente viscosas ou géis na presença de um solvente ou agente de inchamento apropriado, em baixas concentrações. Industrialmente, estas estão associadas aos polissacarídeos e seus derivados (Rodrigues et al., 1993).

Até a década de 1950, os polissacarídeos utilizados no mercado internacional eram produzidos a partir de plantas. A partir de então surgiu uma nova geração desses produtos, de origem microbiana, produzidos sob condições controladas de fermentação, o que os tornam mais estáveis e sem problemas ocasionados em relação às variações climáticas. Estes produtos são usados como agentes espessantes, gelificantes, emulsificantes, floculantes e estabilizantes na indústria alimentícia, farmacêutica, cosmética e petrolífera (Luvielmo e Scamparini, 2009; Rodrigues et al., 1993).

A goma xantana é um polissacarídeo natural, também chamado de biopolímero, produzida por bactérias gram-negativas do gênero Xanthomonas e possui estrutura primária formada por unidades repetidas de pentassacarídeos. Essa goma tem grande importância comercial, é atóxica e pode ser utilizada em alimentos. É o polímero mais utilizado em alimentos no Brasil e no mundo, com aprovação pelo FDA (Food and Drug Administration) desde 1969 para utilização como estabilizante, emulsificante e espessante em alimentos, 
devido às suas características reológicas, como capacidade de alterar as propriedades básicas da água, além de possuir alta viscosidade em baixas concentrações, estabilidade em uma ampla faixa de temperatura e concentração de sais (Borges e Vendruscolo, 2008; Luvielmo et al., 2007; Luvielmo e Scamparini, 2009; Mothé e Correia, 2002; Nery et al., 2008).

O atual processo de produção da xantana consiste nas etapas de obtenção do préinóculo, inóculo, fermentação, remoção das células, precipitação, separação e secagem da goma. No Brasil há um crescente mercado de goma xantana e toda a demanda utilizada é importada. Por isso pesquisas têm sido realizadas baseando-se na produção desta a partir de resíduos industriais, seleção de novas linhagens e adequação nas condições ótimas de crescimento celular, produção, purificação e recuperação do polissacarídeo, com o objetivo de produzir xantana a nível industrial de alta qualidade e rendimento (Luvielmo e Scamparini, 2009).

O soro de leite é um resíduo industrial altamente produzido no Brasil, resultante da indústria de laticínios. Devido a grande quantidade de nutrientes presentes no resíduo e da grande quantidade que é produzida durante a fabricação de queijos, este se torna muito atrativo e economicamente viável em processos fermentativos, por isto já está sendo reconhecido como um ingrediente de alto valor agregado em muitos produtos alimentícios. Têm-se estudado a sua utilização como fonte alternativa de carbono para a obtenção da goma xantana. A utilização do soro como substrato alternativo poderá auxiliar a produção de goma no país, ajudando a reduzir os impactos ambientais oriundos dos efluentes líquidos do processo de fabricação de queijos, pois o soro de leite apresenta característica de ser altamente poluente devido a sua composição rica em nutrientes. Além do que poderia suprir a demanda de goma, visto que toda a xantana utilizada no país é importada (Bezerra, 2008; Mizubuti, 1994; Nery et al., 2008).

Selecionar fontes de carbono para a bactéria Xanthomonas campestris, para obter polissacarídeos em quantidade e com propriedades economicamente interessantes, é um desafio que vem sendo enfrentado por vários grupos de pesquisa. Portanto, embora a tecnologia para produzir goma xantana esteja sedimentada a partir de sacarose como substrato, é necessário em paralelo estudar fontes de carbono alternativas que possam ser viáveis. Neste sentido, o objetivo deste trabalho foi a viabilização da produção de goma xantana utilizando o soro de leite como fonte viável com o intuito de se obter xantanas com elevado rendimento e viscosidade.

\section{METODOLOGIA}

A bactéria utilizada para a produção de goma xantana tanto para o meio padrão de sacarose como o meio alternativo soro de leite foi a cepa de Xanthomonas campestris $\left(\mathrm{n}^{\circ}\right.$ 1537).

Para a preparação do inóculo, foram vertidos $2 \mathrm{~mL}$ de pré-inóculo em meio YM líquido. Os erlenmeyers foram incubados em agitador orbital (shaker) a $180 \mathrm{rpm}$, a uma temperatura de $28^{\circ} \mathrm{C} \pm 2^{\circ} \mathrm{C}$ por 24 horas. 
Após a preparação do inóculo, foi necessário a adição deste em cada erlenmeyer contendo os meios padrão e alternativo, os volumes de água, de inóculo e de soro de leite para o meio alternativo estão representados na Tabela 1. A fermentação foi realizada em shaker a $28 \pm 2^{\circ} \mathrm{C}$ a $250 \mathrm{rpm}$ durante 120 horas para a produção da goma xantana.

Para a produção do biopolímero utilizou-se o meio alternativo soro de leite, sendo necessário avaliar as variáveis e condições do processo utilizando um planejamento estatístico DCCR (Delineamento Composto Central Rotacional) fracionado $2^{2}$ com 4 pontos axiais e triplicata no ponto central, totalizando 11 ensaios conforme apresentado na Tabela 1. A goma xantana produzida pelo meio padrão de sacarose foi obtida de forma a comparar com o meio alternativo. A metodologia de superfície de resposta foi utilizada para determinar a influência das variáveis estudadas e obter a composição do meio fermentativo.

Tabela 1 - Planejamento experimental variando porcentagem de inóculo (\%v/v) e porcentagem de soro de leite $(\% \mathrm{v} / \mathrm{v})$

\begin{tabular}{cccc}
\hline Ensaios & Inóculo $(\% \mathbf{v} / \mathbf{v})$ & Soro de Leite $(\% \mathbf{v} / \mathbf{v})$ & $\begin{array}{c}\text { Volume de água } \\
(\mathbf{m L})\end{array}$ \\
\hline 1 & $-1(11,5)$ & $-1(54)$ & 34,5 \\
2 & $-1(11,5)$ & $+1(76)$ & 12,5 \\
3 & $+1(18,5)$ & $-1(54)$ & 27,5 \\
4 & $+1(18,5)$ & $+1(76)$ & 5,5 \\
5 & $-1,41(10)$ & $0(65)$ & 25 \\
6 & $+1,41(20)$ & $0(65)$ & 15 \\
7 & $0(15)$ & $-1,41(50)$ & 35 \\
8 & $0(15)$ & $+1,41(80)$ & 5 \\
9 & $0(15)$ & $0(65)$ & 20 \\
10 & $0(15)$ & $0(65)$ & 20 \\
11 & $0(15)$ & $0(65)$ & 20 \\
\hline
\end{tabular}

Os ensaios 1 ao 11 foram suplementados com mesma concentração de uréia $(0,01 \mathrm{~g})$ e fosfato de potássio dibásico $\left(\mathrm{K}_{2} \mathrm{HPO}_{4}\right)$ e os $\mathrm{pH}$ foram ajustados para $\mathrm{pH} 7$.

Após a fermentação, os biopolímeros foram precipitados em temperatura ambiente, por uma hora. A concentração utilizada foi de 3:1 de etanol e solução contendo goma xantana. As xantanas foram separadas do meio por método de filtração. Estas foram levadas à estufa por um período aproximado de 24 horas a uma temperatura de $50 \pm 2{ }^{\circ} \mathrm{C}$. Passado o tempo da secagem, as gomas foram levadas ao freezer por mais 24 horas e depois foram levadas ao liofilizador pelo mesmo período.

O rendimento do biopolímero foi obtido pelo método de gravimetria após a liofilização. Para a medição da viscosidade foi necessário a preparação das soluções de $0,5 \%$ $(\mathrm{m} / \mathrm{v})$ de goma xantana utilizando meio padrão de sacarose e meio alternativo soro de leite e após 24 horas foram medidos em viscosímetro. 


\section{RESULTADOS}

A viscosidade aparente das soluções de goma xantana na concentração de $0,5 \%(\mathrm{~m} / \mathrm{v})$ produzida pelas cepas da bactéria $X$. campestris obtida com os meios padrão de sacarose e do meio alternativo contendo soro de leite, foi determinado a partir da taxa de cisalhamento e da temperatura. $\mathrm{O}$ equipamento utilizado foi o viscosímetro de Brookfield com dispositivo de cilindros concêntricos e banho-maria acoplado.

A Tabela 2 a seguir representa os valores encontrados para o meio alternativo soro de leite.

Tabela 2 - Valores das viscosidades obtidas de goma xantana a concentração de 0,5\% (m/v) após a fermentação da bactéria Xanthomonas campestris. A velocidade de rotação empregada foi de 20 rpm

\begin{tabular}{cc}
\hline Ensaio & Viscosidade aparente (m.Pa.s) \\
\hline 1 & 15,4 \\
2 & 5,70 \\
3 & 16,6 \\
4 & 12,6 \\
5 & 16,5 \\
6 & 15,8 \\
7 & - \\
8 & 7,89 \\
9 & 14,0 \\
10 & 14,2 \\
11 & 17,0 \\
\hline
\end{tabular}

$\mathrm{Na}$ concentração de $0,5 \%(\mathrm{~m} / \mathrm{v})$ de goma xantana produzida com sacarose e com o ensaio $7 \mathrm{com}$ meio alternativo, na menor rotação do equipamento $(0,3 \mathrm{rpm})$ as gomas apresentaram torque superior a $90 \%$. O limite de confiabilidade do equipamento é menor que este valor, por isso o resultado não pode ser utilizado.

De acordo com García-Ochoa et al. (2000), a massa molar da goma xantana é influenciada pela sua biossíntese, da linhagem da bactéria utilizada, da composição dos meios e das condições operacionais utilizadas na fermentação. Isto está de acordo com o encontrado, pois os ensaios 1, 3, 5 e 6 produziram gomas com maior viscosidade, o que pode ter produzido xantanas com maior massa molar que nos demais.

O rendimento da goma xantana produzida pela cepa da bactéria $X$. campestris utilizando meio padrão de sacarose e meio alternativo de soro de leite foi obtido por gravimetria após a liofilização. A Tabela 3 a seguir representa os valores encontrados para o meio padrão e o meio alternativo. 
Tabela 3 - Valores dos rendimentos obtidos da produção de goma xantana após a fermentação da bactéria Xanthomonas campestres

\begin{tabular}{ccc}
\hline Substrato & Ensaio & Rendimento $\left(\mathbf{g} . \mathbf{L}^{-1}\right)$ \\
\hline \multirow{2}{*}{ Sacarose } & $\mathbf{1}$ & 1,406 \\
& $\mathbf{2}$ & 1,254 \\
\hline & $\mathbf{1}$ & 3,991 \\
& $\mathbf{2}$ & 3,654 \\
& $\mathbf{3}$ & 1,821 \\
& $\mathbf{4}$ & 3,068 \\
Soro de leite & $\mathbf{5}$ & 3,562 \\
& $\mathbf{6}$ & 2,807 \\
& $\mathbf{7}$ & 1,157 \\
& $\mathbf{8}$ & 5,176 \\
& $\mathbf{9}$ & 2,328 \\
& $\mathbf{1 0}$ & 2,545 \\
& $\mathbf{1 1}$ & 2,566 \\
\hline
\end{tabular}

Os resultados foram obtidos por gravimentria logo após a liofilização dos onze ensaios. Como pode-se perceber as gomas xantanas que apresentaram maior rendimento foram a partir dos ensaios 1, 2, 4, 5 e 8. Isto pode ter ocorrido pelo fato das condições de processo nestes meios terem sido mais favoráveis ao micro-organismo durante a fermentação, ou seja, a bactéria se adaptou melhor para a bioconversão nestas condições ocasionando em gomas com diferentes massas molares do que as demais produzindo maior rendimento do biopolímero.

De acordo com Nery et al. (2008), os valores da produção de goma xantana obtidas a partir de substrato alternativo utilizando a cepa 2103 e 1866 foram 21,90 g.L ${ }^{-1}$ e 12,36 g.L $\mathrm{L}^{-1}$, respectivamente, enquanto a produção da xantana a partir de sacarose foi de $6,62 \mathrm{~g} . \mathrm{L}^{-1}$, sendo que o meio alternativo teve produção três vezes maior que a produção com meio padrão. As condições do processo foram as mesmas empregadas para o experimento descrito, temperatura de $28^{\circ} \mathrm{C}, 250 \mathrm{rpm}$ e 120 horas de fermentação.

Apesar das mesmas condições impostas no experimento de Nery et al. (2008) e o aqui proposto, percebe-se a grande diferença de rendimento, isto pode ser causado pela diferente linhagem utilizada para a produção da xantana bem como das diferenças nas condições como os volumes de soro de leite e de inóculo utilizados e de suplementação de meio.

Segundo Menezes et al. (2012), a produção de goma xantana utilizando sacarose como fonte de carbono variou de 0,64 g.L $\mathrm{L}^{-1}$ a $9,67 \mathrm{~g} . \mathrm{L}^{-1}$, com uma média de 4,86 g.L $\mathrm{L}^{-1}$. A média encontrada pelo experimento com o meio padrão de sacarose foi de $1,33 \mathrm{~g} . \mathrm{L}^{-1}$ e de meio alternativo contendo soro de leite foi de 2,97 g.L. $\mathrm{L}^{-1}$, obtendo maior produção com o meio alternativo.

A viscosidade e o rendimento da goma xantana não seguem o mesmo comportamento. Observa-se na superfície de resposta na Figura 1B que existe uma tendência de encontrar uma faixa ótima de rendimento de xantana quando diminuir o volume de soro e aumentar o 
percentual de inóculo. Isto já não ocorre com a viscosidade, neste caso, é necessário diminuir a concentração de inóculo para se obter gomas com maior viscosidade (Figura 1A).
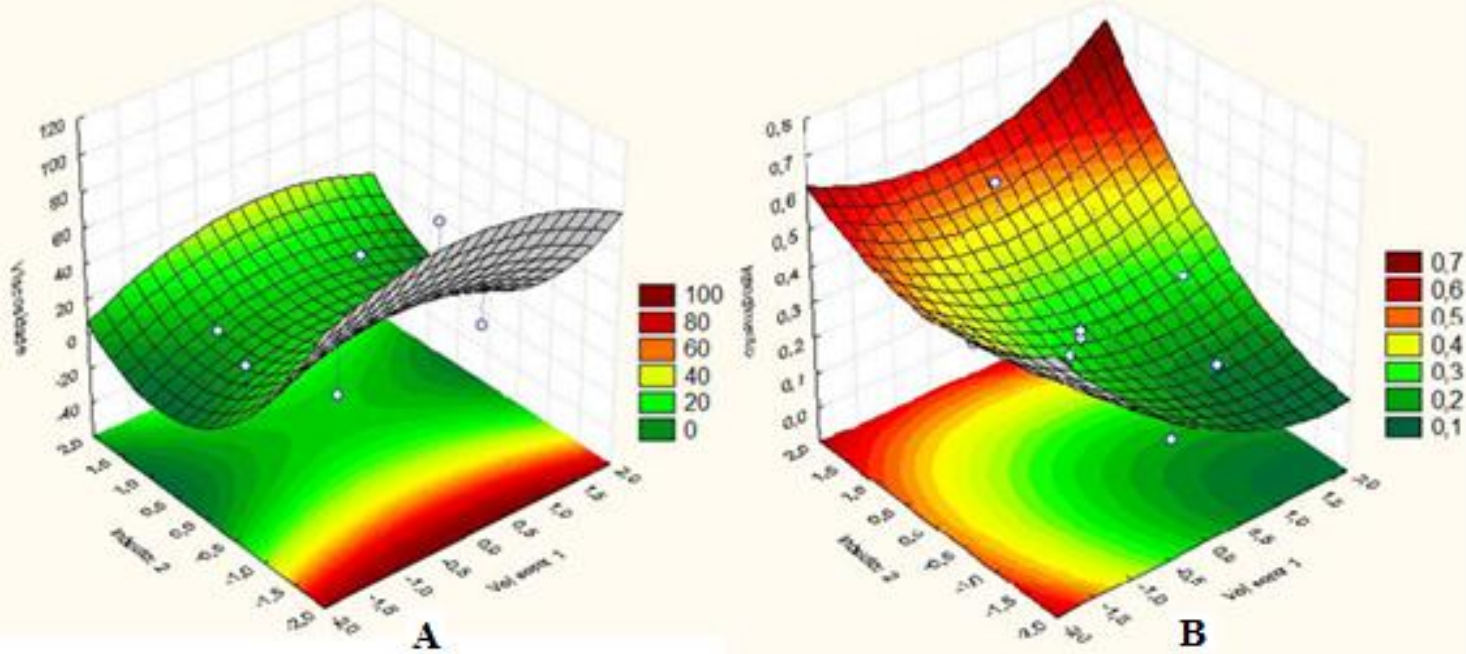

Figura 1 - Superfície de resposta com o comportamento da viscosidade aparente (A) e do rendimento (B) da goma xantana obtida pela cepa 1537 da bactéria X. campestris em relação ao volume de soro e volume de inóculo.

Comparando os valores de produção de gomas xantana obtidas a partir da sacarose e de soro de leite, constatam-se rendimentos maiores para a bioconversão a partir da fonte alternativa. Esse resultado indica que é possível obter goma xantana a partir do meio alternativo analisado, reduzindo os custos de produção, já que o soro de leite é um subproduto proveniente da agroindústria.

Observa-se na superfície de resposta (Figura 1B) obtida a partir do modelo empírico que existe uma tendência de encontrar uma faixa ótima de rendimento de goma xantana quando diminuir o volume de soro e aumentar o percentual de inóculo. É necessário o aumento dos valores de inóculo e a diminuição da concentração do volume de soro utilizada para visualizar melhor o ponto ótimo da produção de goma xantana.

Para a análise da viscosidade, conclui-se que o meio padrão de sacarose produz soluções altamente viscosas em comparação ao meio alternativo de soro de leite. Existe uma tendência de encontrar uma faixa ótima de viscosidade de goma xantana quando diminuir a concentração de inóculo (Figura 1A). É necessário diminuir os valores de inóculo para visualizar melhor o ponto ótimo de viscosidade da xantana.

No momento estamos realizando experimentos, fixando o valor de $\mathrm{pH}$ e o volume de inóculo e variando a concentração de soro e a fonte de nitrogênio. Com este experimento, pretendemos encontrar as condições que favoreçam maiores rendimentos de produção de goma com alta viscosidade. 


\section{CONCLUSÕES}

O uso de soro de leite, como substrato alternativo à sacarose, para produção de goma xantana mostra-se uma alternativa interessante, sobretudo pelo fato do substrato em questão ser um resíduo agroindustrial importante. No presente estudo, nas condições experimentais adotadas, o rendimento médio de goma produzida a partir do substrato padrão sacarose foi de 1,33 g. $\mathrm{L}^{-1}$ e de soro de leite foi de $2,97 \mathrm{~g} . \mathrm{L}^{-1}$. Os resultados do planejamento experimental realizado mostraram que as variáveis: volume de soro de leite e volume de inóculo influenciaram no rendimento e na viscosidade das gomas produzidas. Observou-se que existe uma tendência de encontrar uma faixa ótima de rendimento de xantana quando diminuir o volume de soro e aumentar o percentual de inóculo. Isto já não ocorre com a viscosidade, neste caso, é necessário diminuir a concentração de inóculo para se obter gomas com maior viscosidade. Os resultados prévios apresentados neste trabalho estão sendo utilizados para realizar novos experimentos com o intuito de produzir gomas com altos rendimentos e altas viscosidades. A grande vantagem deste processo é que as gomas produzidas a partir da fermentação do soro de leite, teriam um baixo custo comparado ao custo de gomas produzidas a partir de sacarose e ainda aproveitaria o soro de leite que é um resíduo agroindustrial que quando lançado nos mananciais, causa sérios problemas ambientais.

\section{REFERÊNCIAS BIBLIOGRÁFICAS}

BEZERRA, J. R. M. Tecnologia de fabricação de derivados do leite. Universidade Estadual do Centro-Oeste, UNICENTRO. Guarapuava, 2008.

BORGES, C. D.; VENDRUSCOLO, C. T. Goma Xantana: características e condições operacionais de produção. Universidade Estadual de Londrina. Londrina, 2008.

GARCÍA-OCHOA, F. SANTOS, V. E.; CASAS, J. A.; GÓMEZ, E. Xanthan gum: production, recovery, and properties. Biotechnology advances, v. 18, p. 549-579, 2000.

LUVIELMO, M. M.; SCAMPARINI, A. R. P. Goma xantana: produção, recuperação, propriedades e aplicação. Estudos tecnológicos - Vol. 5, n.1, p. 50-67, 2009.

LUVIELMO, M. M.; VENDRUSCOLO, C. T.; SCAMPARINI, A. R. P. Seleção de linhagens de Xanthomonas campestris para a produção de goma xantana. Universidade Estadual de Londrina. Semina: Ciências Exatas e Tecnológicas, Londrina, v. 28, n.2, p. 161$172,2007$.

MENEZES, J. D. S.; DRUZIAN, J. I.; PADIlHA, F. F.; DE SOUZA, R. R. Produção biotecnológica de goma xantana em alguns resíduos agroindustriais, caracterização e aplicações. Universidade de Santa Maria. Revista Eletrônica em Gestão, Educação e Tecnologia Ambiental, vol.8, n.8, 2012.

MOTHÉ, C. G.; CORREIA, D. Z., Caracterização reológica de blendas de gomas cajueiro e xantana em suco. Universidade Federal do Rio de Janeiro. Revista Analytica, n.2, 2002. 
MIZUBUTI, I. Y. Soro de Leite: Composição, Processamento e Utilização na Alimentação. Universidade Estadual de Londrina. Semina: Ci. Agr., vol. 15, n.1, p. 80-94, Londrina, 1994.

NERY, T. B. R.; BRANDÃO, L. V.; ESPERIDIÃO, M. C. A.; DRUZIAN, J. I. Biossíntese de goma xantana a partir da fermentação de soro de leite: rendimento e viscosidade. Universidade Federal de Bahia. Química Nova. Vol. 31, n.8, p. 1937-1941, São Paulo, 2008.

RODRIGUES, J. F.; PAULA, R. C. M.; COSTA, S. M. O. Métodos de Isolamento de Gomas Naturais: Comparação Através da Goma do Cajueiro (Anacardium occidentale L.). Universidade Federal do Ceará. Fortaleza, 1993. 